\title{
RELAÇÕES ÉTNICO-RACIAIS NA EDUCAÇÃO INFANTIL EM ITAPETINGA-BA: o que dizem as crianças?
}

\author{
José Valdir Jesus de Santanal \\ Rainan Sena Santos Menezes² \\ Reginaldo Santos Pereira ${ }^{3}$
}

\section{RESUMO}

Nessa pesquisa tivemos como objetivos compreender como crianças elaboram sentidos acerca de seus pertencimentos étnico-raciais e como vivenciam e acionam noções como racismo, discriminação racial em suas relações com outras crianças e com os adultos. A pesquisa foi realizada com crianças da educação infantil, em uma escola pública localizada no município de Itapetinga, estado da Bahia. Utilizamos de uma abordagem de natureza qualitativa, de caráter descritivo e de natureza etnográfica (LÜDKE e ANDRÉ, 2013; AMADO, CRUSOÉ, VAZ-REBELO, 2017). Muitas crianças, ao indicarem os padrões de beleza hegemônicos em nossa sociedade, expressaram falas e atitudes de negação de seus pertencimentos étnico-raciais, especialmente as crianças negras. Contudo, esse processo de "captura" não ocorre de forma total, posto que as crianças reagem ao "privilégio simbólico da brancura" (BENTO, 2009).

Palavras-chave: Crianças. Relações raciais. Sociologia da infância.

ETHNIC-RACIAL RELATIONS IN CHILDREN'S EDUCATION IN ITAPETINGA-BA: what do children say?

\begin{abstract}
In this research we aimed to understand how children elaborate meanings about their ethnic-racial belonging and how they experience and trigger notions as racism, racial discrimination in their relations with other children and adults. The research was carried out with children from a public school located in Itapetinga, state of Bahia. We used a qualitative, descriptive and ethnographic approach (LÜDKE and ANDRÉ, 2013; AMADO, CRUSOÉ, VAZ-REBELO, 2017). Several children, while indicating the

\footnotetext{
1 Doutor em Antropologia Social pela Universidade Federal de São Carlos; professor adjunto da Universidade Estadual do Sudoeste da Bahia e do Programa de Pós-Graduação em Relações Étnicas e Contemporaneidade, Campus de Itapetinga/BA. E-mail: santanavaldao@yahoo.com.br

2 Graduado em Pedagogia pela Universidade Estadual do Sudoeste da Bahia; professor da rede privada do município de Vitória da Conquista/BA. E-mail: rai_sena10@hotmail.com

3 Doutor em Educação pela Universidade Federal de São Carlos; professor adjunto da Universidade Estadual do Sudoeste da Bahia e do Programa de Pós-Graduação em Educação, Vitória da Conquista/BA. E-mail: reginaldouesb@gmail.com
} 
hegemonic patterns of beauty in our society, have expressed discourses and attitudes of denial of their ethnic-racial belonging, especially black children. However, this process of "capture" does not occur in full, since children react to the "symbolic privilege of whiteness" (BENTO, 2009).

Keywords: Children. Racial relations. Childhood sociology.

\section{RELACIONES ÉTNICO-RACIALES EN LA EDUCACIÓN INFANTIL EN ITAPETINGA-}

\section{BA. ¿lo que dicen los niños?}

\section{RESUMEN}

En esta pesquisa tuvimos como objetivos comprender como niños desarrollan sentidos acerca de sus pertenencias étnico-raciales y como vivencian y accionan nociones como racismo, discriminación racial en sus relaciones con otros niños y con los adultos. La pesquisa ha sido realizada con niños de la educación infantil, en una escuela pública situada en la ciudad de Itapetinga, Estado de Bahia. Utilizamos de una abordaje de naturaleza cualitativa, de carácter descriptivo y de naturaleza etnográfica (LÜDKE e ANDRÉ, 2013; AMADO, CRUSOÉ, VAZ-REBELO, 2017). Muchos niños, al apuntaren las normas de belleza hegemónicas en nuestra sociedad, expresaran discursos y actitudes de negación de sus pertenencias étnico-raciales, especialmente los niños negros. Sin embargo, ese proceso de "captación" no ocurre de forma total, puesto que los niños reaccionan al "privilegio simbólico de la blancura" (BENTO, 2009).

Palabras clave: Niños. Relaciones étnicos-raciales. Sociología de la infancia.

\section{INTRODUÇÃO}

As pesquisas sobre relações raciais que abordam a questão da criança negra no contexto escolar, em sua grande maioria, apresentam-na com problemas de relacionamento com seus colegas e professores, ocasionados pelos conflitos étnico-raciais, especialmente no tocante à cor da pele, gerando uma relação conflituosa e quase sempre nociva para os que acabam sendo rejeitados por seus atributos físicos (FINCO e OLIVEIRA, 2011). Ao refletir sobre muitas dessas pesquisas, Abramowicz, Oliveira e Rodrigues (2010) afirmam que elas apresentam um caráter de denúncia em torno das práticas racistas e dos processos de discriminação que recaem sobre as crianças, especialmente as negras, no espaço escolar.

Pesquisas mais recentes, a exemplo de Santiago (2014), Abramowicz e Oliveira (2010), inspiradas pela sociologia da infância, trazem novas questões 
para o debate acerca das relações raciais, criança e infância. A sociologia da infância e a antropologia da criança advogam que crianças e infâncias são produzidas socialmente e que não são dados universais nem naturais. Nisso, crianças possuem agência, são portadoras e construtoras de cultura e, nesse sentido, têm muito a nos dizer sobre diversos aspectos da vida social, inclusive sobre as relações raciais vivenciadas no contexto escolar.

Firmada na década de 1990, a sociologia da infância é um campo de estudo que, segundo Sarmento (2005), tem como um dos principais objetivos investigar a sociedade a partir de um ponto de vista que visa as crianças como sujeitos ativos da pesquisa sociológica, ampliando o conhecimento não apenas sobre a infância, mas também sobre a sociedade. Nisso, segundo Abramowicz e Oliveira,

\begin{abstract}
A sociologia da infância surgiu na década de 90 para disputar esse campo teórico: a criança e a infância, abandonado pela própria sociologia, apesar de encontrarmos pistas e pressupostos desse campo desde a década de 1920. Aquilo que virá a ser chamado de sociologia da infância apareceu na Europa a partir da inflexão da concepção de socialização, que vinha sendo pensada até então segundo os aportes durkheimianos (2012, p. 48).
\end{abstract}

Nessa perspectiva, olhar a criança como sujeito passivo das relações e construções sociais nos limita a pensar neste sujeito enquanto cooperador e construtor dessas relações, posto que ao obliterarmos sua participação acabamos por privar as crianças de exercerem seus direitos e imprimirem suas perspectivas e pontos de vista acerca de suas produções sociais e culturais.

Estudiosos da sociologia da infância e da antropologia da criança, a exemplo de Corsaro $(2009,2011)$, Abramowicz e Oliveira (2012), Abramowicz (2011), Nascimento (2011), Sarmento (2005, 2009), Gomes (2009), Finco e Oliveira (2011), Cohn (2005) Delgado e Müller (2005), Prout (2010), Lee (2010), Delgado (2011) nos apresentam o potencial teórico/analítico proporcionado por esse "novo" campo do conhecimento, ao mesmo tempo em que nos chamam a atenção que, para construir esse novo paradigma, além de conceber a infância como uma construção histórica, cultural e política é 
necessário levar em consideração diferentes variáveis, como classe social, sexo, gênero, pertencimento étnico-racial, dentre outras categorias.

Dessa forma, segundo Rosemberg (2012), levar a sério o modelo proposto pela sociologia da infância implica em romper com os paradigmas adultocêntricos e com a concepção de que a criança "deve ser aculturada ao mundo social via processo de socialização entendido como condicionamento das normas sociais, impostos de "cima" (universo adulto) para "baixo" (universo infantil)" (ROSEMBERG, 2012, p. 23), herdeiros da tradição durkheimiana. Ademais, conforme Delgado e Müller $(2005$, p. 3) "se as crianças interagem no mundo adulto porque negociam, compartilham e criam culturas, necessitamos pensar em metodologias ${ }^{4}$ que realmente tenham como foco suas vozes, olhares, experiências e pontos de vista".

Cohn (2005), tendo como referência o contexto da etnologia indígena, em especial os Xikrin, defende a ideia de que "a criança atuante é aquela que têm um papel ativo na constituição das relações sociais em que se engaja, não sendo, portanto, passiva na incorporação de papeis e comportamentos sociais". Conforme a autora,

Reconhecê-lo é assumir que ela não é um "adulto em miniatura", ou alguém que treina para a vida adulta. É entender que, onde quer que seja, ela interage ativamente com os adultos $e$ as outras crianças, com o mundo, sendo parte importante na consolidação dos papéis que assume e de suas relações (COHN, 2005, p. 27-28).

Abramowicz, Oliveria e Rodrigues (2010), Abramowicz e Oliveira (2010, 2012), Nunes $(2015,2016$, 2017), Souza (2016), Abramowicz, Cruz e Rodrigues (2017), Finco e Oliveira (2011) e Santiago (2014) têm nos chamado a atenção para a necessidade de levarmos em consideração, nos estudos com aportes na sociologia da infância, do marcador racial e, nesse sentido, defendem que não é possível uma sociologia da infância brasileira que não leve em conta a categoria raça.

\footnotetext{
${ }^{4}$ Sobre questões de ordem metodológica e ética nas pesquisas com crianças, vê Carvalho e Müller (2010), Corsaro (2005) e Ferreira (2009).
} 
A proposta do nosso debate, a partir da sociologia da infância no Brasil, não pode ignorar a especificidade do nosso contexto, regida de forma explícita pela questão racial. [...] Essa realidade demanda pesquisas que tenham referencial teórico-metodológico para pensar a criança negra enquanto "ator social" que se constitui e é constituída nas relações sociais de determinada forma, e essa processualidade de se constituir como criança e negra que temos que buscar configurar (ABRAMOWICZ; OLIVEIRA, 2012, p. 53).

Pensar crianças e infâncias de forma heterogênea é possibilitar uma melhor compreensão acerca de suas diversidades e diferenças, de seus diferentes pontos de vistas em torno de distintas questões, a exemplo das questões étnico-raciais, que as crianças vivenciam nas relações com os seus pares e com os adultos. É este o nosso empreendimento, tendo como interlocutoras crianças da educação infantil, de uma escola localizada no município de Itapetinga-BA. Cabe ressaltar, ademias, que as reflexões apresentadas nesse texto são resultado de pesquisas que temos desenvolvido na cidade de Itapetinga-BA, na Universidade Estadual do Sudoeste da Bahia, desde 2015, a partir do projeto de pesquisa intitulado "Do ponto de vista das crianças: educação e relações étnico-raciais em escolas públicas do município de ltapetinga-BA".

\section{CRIANÇAS E RELAÇÕES ÉTNICO-RACIAIS: situando algumas pesquisas}

A pesquisa de Algarve (2004), realizada em São Carlos, SP, analisou as concepções de crianças brancas e negras frente aos negros e sua cultura, refletindo acerca das características de um trabalho que visa combater o racismo e as discriminações, a partir do que ela denominou de "Cantinho das africanidades". Este "Cantinho" continha objetos e materiais que ressaltavam a cultura africana, bem como imagens que retratavam as relações de crianças com objetos, textos e principalmente com outras crianças. A autora identificou que houve uma melhora significativa nas relações de crianças negras e brancas, maior auto aceitação por parte das crianças negras em relação a seu pertencimento étnico-racial, elevação de sua autoestima, posto que, no decorrer do processo, se sentiram participantes de uma cultura bonita, rica e importante; por fim, alargamento 
da compreensão das crianças brancas em torno dos valores civilizatórios africano-brasileiro.

\begin{abstract}
A experiência desenvolvida por mim - pesquisadora, juntamente com a professora Elaine Bedendo, na escola EMEB prof ${ }^{\circ}$. Afonso Fioca Vitali (CAIC), em São Carlos/SP, - mostra que, quando os professores sentem a importância de desenvolver trabalhos de valorização das diferentes culturas que compõem a nação brasileira e a identidade pessoal de cada aluno, podem diminuir as discriminações e os preconceitos entre as crianças da sala, pois elas se reeducam, passam a respeitar os outros, suas diferenças, os grupos do qual fazem parte, suas culturas e suas histórias. Como se vê, a experiência desenvolvida com o Cantinho de Africanidades mostra que ao valorizar as diferentes culturas que compõem a sociedade brasileira, as escolas estarão contribuindo para as relações positivas entre os alunos (ALGARVE, 2004, p. 133-134).
\end{abstract}

Silva (2009), em sua pesquisa, de inspiração etnográfica, realizada no município de Niterói5, buscou compreender as relações que as crianças negras estabelecem com seus professores, com as crianças não negras e com os demais grupos pertencentes ao ambiente escolar. Utilizou-se dos aportes teórico/metodológicos da sociologia da infância, dos estudos sobre a perspectiva multicultural/intercultural sobre o cotidiano escolar e de pesquisadores que têm discutido sobre as relações étnico-raciais entre crianças.

O estudo de caso se desenvolveu procurando-se observar as crianças negras e suas relações com as demais crianças no cotidiano escolar, principalmente no cotidiano de uma sala de aula, mas também no refeitório, no recreio, nos corredores, na aula de educação física, na entrada e na saída da escola (SILVA, 2009, p. 86).

Conforme Silva, as crianças, de forma geral, atribuem ao preto/negro um valor negativo, uma vez que ser negro significa ser feio, ter um cabelo espetado e duro, morar em local ruim, na favela e em barraco. "Há uma

\footnotetext{
${ }^{5}$ A pesquisa de campo, de caráter qualitativo e inspiração etnográfica, foi realizada no primeiro semestre de 2008 e supôs observações sistemáticas no cotidiano de uma sala de aula, quatro dias na semana, durante cinco meses, assim de diferentes espaços escolares corredor, recreio, refeitório, entrada e saída, etc., assim como entrevistas com membros do corpo docente da escola e diálogos informais com as crianças. A turma estava formada por 28 crianças, de faixa etária de 7 a 14 anos, do $1^{a}$ ano do Ensino Fundamental (SILVA, 2009, p. 8).
} 
negatividade atribuída à categoria preto/negro que coloca as crianças nela classificadas em situações de inferiorização, assim como são objeto de gozações e xingamentos". Ademais, "[...] Os meninos negros também se encontravam em situação de desvantagem em relação aos meninos brancos, em defasagem série/idade em relação à série que estavam cursando" (2009, p. 118).

Foi possível notar também, através das falas das crianças e nas entrevistas com as professoras, que parece existir uma relação entre desigualdade social e características étnicorraciais, pois a maioria das crianças negras vivia em condições precárias. Elas reconheciam e falavam sobre suas precárias condições de vida, o trabalho de seus pais, a moradia e a realidade das comunidades em que viviam. A grande maioria era beneficiária do Bolsa Família como fonte de renda. Essas mesmas crianças apresentavam os piores rendimentos em relação ao desenvolvimento da leitura e da escrita na sala de aula pesquisada. Tal fato foi percebido principalmente através das histórias relatadas pelas próprias crianças sobre suas vidas e seus contextos socioculturais e pelos depoimentos das professoras (2009, p. 144-145).

Por fim, a autora destaca a importância da lei 10.639/03 como possibilidade de criar experiências pedagógicas de combate às atitudes discriminatórias e preconceituosas, como as relevadas a partir de sua pesquisa.

A pesquisa de Trinidad (2011) buscou analisar como as crianças de educação infantil compreendiam a identificação étnico-racial, quais critérios elas estabeleciam e como os espaços de educação infantil contribuíam para a construção desses critérios. A pesquisa foi realizada em uma escola localizada na zona oeste do estado de São Paulo e teve como participante 33 crianças de 4 e 5 anos. A autora optou por uma abordagem etnográfica e por procedimentos de "coleta de dados" que evolviam a observação participante, contação de histórias, análises documentais, entre outros. O referencial teórico foi construído a partir de três abordagens: as teorias acerca da identificação étnico-racial, que mobilizam a categoria racial, entendendo-a como construção social; a proposta sócio histórica do campo da Psicologia, especialmente as categorias "sentido" e "significado"; a sociologia da infância, que compreende a criança como ator social 
legítimo, produtor de símbolos, representações e crenças que atuam na produção de suas próprias culturas.

$O$ reconhecimento de que as pessoas podem ser brancas ou negras desenvolve - se por volta dos 3 e 4 anos de idade. As crianças negras ou brancas só se reconhecem como membros de um desses grupos após os 3 anos de idade. Até os 7 anos de idade, as crianças acreditam que a identidade étnica é mutável. A predisposição para se identificar como "branca" desenvolvese, em geral, após o contato com indivíduos de grupos étnicos diferentes daqueles a que a criança pertence (TRINIDAD, 2011, p. 125).

Os resultados de sua pesquisa, apresentada como tese de doutorado, mostraram que as crianças de pouca idade (4 e 5 anos) já reconhecem e empregam as categorias étnico-raciais, mesmo que em suas brincadeiras e relações não selecionem seus pares tendo como critério a cor da pele; contudo, expressam o desejo de ter características associadas ao grupo de pessoas brancas, especialmente no que diz respeito ao cabelo e à cor da pele.

[...] As crianças estudadas, com traços relacionados ao grupo negro, explicitaram não se identificarem com algumas de suas características, indicando uma valoração negativa de seu grupo étnico-racial. A maioria das crianças almejavam que seus cabelos encaracolados, crespos, duros - fossem substituídos dos outros, lisos e loiros. [...] Já nessa etapa da vida, as crianças haviam se apropriado de identificações étnico-raciais, associando-as a valores presentes em seu entorno, que se manifestavam por meio da negação de traços associados aos negros. Em relação às crianças brancas, ou aquelas que tinham tais feições, o desejo de mudar algo em sua aparência foi raro (TRINIDAD, 2011, p. 151-152).

A autora ressalta que o caráter positivo da cor/raça branca vigorava entre as crianças brancas e era por elas salientado e reproduzido. Se nas brincadeiras realizadas pelas crianças não foram "identificados privilégios nem escolhas pautadas pela cor/raça, suas falas constantemente mencionavam essa questão em situações negativas, indicando que preconceitos já faziam parte do imaginário e do repertório infantil" (p. 153). Ou seja, através das palavras, da linguagem, as crianças verbalizavam e imprimiam sentidos sobre si e sobre o outro, no tocante às identificações étnico-raciais. Nesse sentido, segundo Trinidad (2011, p. 166) "o espaço da 
educação infantil é rico para observar como crianças pequenas se apropriam de suas identificações étnico-raciais e as explicitam", por mais que esse espaço tenha sido "injustamente esquecido quando se trata de conhecer os sentidos e os significados construídos por crianças pequenas quanto à condição humana e à identificação étnico-racial" (p. 166).

Bento (2012), ao recuperar pesquisas sobre a construção da identidade racial de crianças pequenas, afirma que, para o movimento negro, a questão da construção identitária se colocou como uma das maiores preocupações deste movimento, posto que, numa sociedade marcada pelo racismo, assumir-se negro é tarefa difícil, na medida em que esta mesma sociedade atribui ao povo negro a condição de pobreza, inferioridade, feiura, incompetência e atraso cultural. Contudo, segundo a autora, são raríssimas as pesquisas que têm como objetivo compreender a construção da identidade na primeira infância, considerada por ela como "nascedouro do pensamento e da identidade racial" (BENTO, 2012, p. 100).

Muito cedo elementos da identidade racial emergem na vida das crianças; diferentes autores, destacam que, entre 3 e 5 anos, a criança já percebe a diferença racial e, ao percebê-la, interpreta e hierarquiza; crianças pequenas são particularmente atentas ao que é socialmente valorizado ou desvalorizado, percebendo rapidamente o fenótipo que mais agrada e aquele que não é bem aceito; crianças pequenas brancas se mostram confortáveis em sua condição de brancas e raramente explicitam o desejo de ter outra cor de pele ou outro tipo de cabelo. Com frequência explicitam que branco é bonito e preto é feio (apontando bonecas, personagens de livros, colegas, professoras); crianças pequenas negras se mostram desconfortáveis em sua condição de negras, porém raramente reagem à colocação de que preto é feio. Quando reagem e pedem ajuda ao professor, este não sabe o que fazer e/ou silencia. Crianças negras revelam o desejo de mudar o tipo de cabelo e a cor da pele; a criança negra parece mais agudamente atenta à diferença racial do que a branca (BENTO, 2012, p. 101).

Os aspectos apresentados por Bento, recorrentes em pesquisas sobre a temática, a exemplo das realizadas por Cavalleiro (1998), Oliveira (2004), Fazzi (2006), Trinidad (2011) são pertinentes e nos ajudam a compreender muitas das questões e situações encontradas em nossa pesquisa, que retomaremos mais a frente, na análise dos dados. 
Em pesquisa sobre crianças, infâncias e relações étnico-raciais Gaudio e Rocha (2013) apresentam reflexões importantes, tendo como foco uma instituição de educação infantil. As autoras identificaram o fator corporal como o primeiro critério de classificação nas relações entre as crianças: gordo e magro, bonito e feio, preto e branco foram encontrados como determinantes desse processo de caracterização do outro, tendo destaque sobre a valorização de padrões estéticos definidos socialmente como o branco e o magro. Sobre a questão corporal e a construção da identidade, as autoras afirmam que "no processo de formação da identidade das crianças pequenas, a aparência e as características físicas do "outro" são elementos essenciais, no qual o corpo pode representar um importante papel na construção de uma autoestima positiva" (2013, p. 43).

Em relação à questão corporal, as autoras relatam uma cena vivenciada por ambas no refeitório da escola. Uma criança, negra, participante da pesquisa, estava almoçando e, de repente, volta-se a uma das pesquisadoras afirmando que aquela comida iria mudar a cor da sua pele. A pesquisadora indaga-a sobre o desejo em querer mudar a cor da pele e a criança justifica porque acha a cor branca mais bonita. "A partir da narrativa, podemos perceber o desejo de uma criança negra tornar-se branca através da ingestão de alimentos" (GAUDIO e ROCHA, 2013, p. 45).

Outra preocupação levantada pelas autoras diz respeito à estética do cabelo. As crianças, ao acordarem do "momento do soninho", logo se preocupavam com a arrumação dos cabelos, pedindo-as que penteassem e arrumassem, principalmente as que tinham cabelos crespos e ondulados. "Com base na investigação realizada, as crianças demonstraram que aparência física é um elemento central na organização de suas relações, privilegiando características como a cor da pele branca" (GAUDIO e ROCHA, 2013, p. 47).

A tese de Nunes (2017), fruto de uma etnografia realizada com crianças de uma turma de Educação Infantil na escola municipal Malê Debalê, em Salvador/BA, é um bom exemplo do quanto o estudo das relações étnico-raciais tem a ganhar com os aportes teórico/metodológicos 
trazidos pela sociologia da infância. A análise empreendida pela autora ganha em sofisticação analítica, ao mesmo tempo em que apresenta a potência das perspectivas das crianças em torno das questões raciais, do corpo, mas não somente.

A pesquisa demonstrou que embora as crianças da referida escola estejam em um espaço em que as culturas negras são vivenciadas pelas crianças, posto que a escola localizava-se dentro de um bloco afro com o mesmo nome da instituição (Malê Debalê), tanto os meninos quanto "as meninas negras ainda são submetidos/as às normas de raça e sexo-gênero, acrescidas pelas imposições de idade, demonstrando o caráter fundamental do debate interseccional para alcançarmos as crianças negras" (NUNES, 2017, p. 9).

No que tange aos corpos das crianças, estes movem-se através de gingas de corpo e gingas de palavra, organizadas individual e coletivamente para burlar os espaços-tempos definidos pela escola $e$ as ordens institucionais adultas ocidentais. Entre mandingas e gingas, as crianças "brincam" não apenas com brinquedos, pessoas e coisas, mas também com a própria vida, recuando e atacando, tal qual num jogo de capoeira e, ao mesmo tempo, se acomodam, resistem e transformam (2017, p. 10).

Por fim, afirma a autora,

Nessa pesquisa quis ir além do enquadramento que confina as crianças negras a experiências limitadoras de sua condição humana por conta da raça, mas não posso furtar-me de constatar que a negação tem se configurado como uma das estratégias de jogo mais presente em suas existências. Essa constatação sobre negação no entanto, não se refere ao campo estudado, pois ali a negaça não era um movimento permanente realizado pelas crianças para serem vistas ou continuarem vivas; era um movimento possível, mas não o único. Assim, suas mandingas e gingas davam conta de outros aspectos que não os raciais, a saber: a própria condição da infância, do sexo-gênero e da classe. Retifica-se, assim, a importância que há para as crianças negras os espaços de afirmação e de acolhimento como a escola do Malê para seguirem sendo quem são, a despeito da ideia corrente traduzida em racismo e adultocentrismo cotidianos, que the dizem que elas não são e nunca serão. A escola do Malê, em consonância com os lugares onde a população negra organizou sua luta pela educação, soma esforços para manter vivo um dos muitos espaços em que seguimos aprendendo a ser e tornar-se (2017, p. 341-342). 
Impossível apresentar, nesse texto, todas as questões abordadas e analisadas por Nunes, mas queremos reiterar o rendimento/potência de sua pesquisa, posto que abre novas possibilidades, tanto analíticas quanto metodológicas, no campo da pesquisa com e sobre crianças.

\section{ASPECTOS METODOLÓGICOS}

Esta pesquisa enquadra-se em uma abordagem de natureza qualitativa, de caráter descritivo e de natureza etnográfica (LÜDKE e ANDRÉ, 2013; AMADO, CRUSOÉ, VAZ-REBELO, 2017). O estudo qualitativo não se preocupa com procedimentos de quantificação, mas sim com o aprofundamento da apreensão de uma realidade de determinado grupo social, como salienta Minayo (2010). Nesse sentido,

As abordagens qualitativas se conformam melhor a investigações de grupos e segmentos delimitados e focalizados, de histórias sociais sob a ótica dos atores, de relações e para análises de discursos e de documentos (MINAYO, 2010. p. 57).

Em se tratando de pesquisas com crianças, a primeira questão a ser pontuada no cuidado com a etnografia é a entrada em campo. William Corsaro (2005), etnógrafo e estudioso da sociologia da infância, ressalta que a entrada do adulto no universo infantil é tensa e conflituosa, principalmente no tocante às diferenças existentes entre adultos e crianças; segundo ele, para a realização de um trabalho eficiente, é preciso buscar, de maneira adequada, adentrar-se "no ambiente" de modo que a sua presença não se torne um empecilho para o desenvolvimento da pesquisa. Nessa perspectiva, a etnografia se torna o método mais adequado para a produção de dados junto a pesquisa com criança. "A etnografia [...] exige que os pesquisadores entrem e sejam aceitos na vida daqueles que estudam e dela participem. Neste sentido, por assim dizer, a etnografia envolve tornarse nativo" (CORSARO, 2005, p. 446).

A investigação foi realizada num período de aproximadamente cinco meses, entre agosto e dezembro de 2015. Os sujeitos dessa pesquisa foram 19 
crianças de uma escola de educação infantil, localizada no município de Itapetinga/BA, sendol0 do sexo masculino e 9 do sexo feminino, com faixa estaria entre 5 e 6 anos.

Optamos pela observação participante e pela realização do que denominamos nesse trabalho de "intervenções pedagógicas" que, na verdade, foram situações/técnicas/dispositivos acionados pelos pesquisadores no sentido de produzir os dados em campo (mas a frente, descreveremos essas intervenções/técnicas). Segundo Queiroz,

\begin{abstract}
A observação participante é uma das técnicas muito utilizada pelos pesquisadores que adotam a abordagem qualitativa e consiste na inserção do pesquisador no interior do grupo observado, tornando-se parte dele, interagindo por longos períodos com os sujeitos, buscando partilhar o seu cotidiano para sentir o que significa estar naquela situação (2007, p. 278).
\end{abstract}

Apoiando-nos na perspectiva da observação participante e no cuidado ao adentrar no ambiente infantil, buscamos, nos dois primeiros meses da pesquisa (agosto e setembro), observar as ações desenvolvidas pelas crianças nos diversos espaços presentes da unidade escolar. Com caderno e caneta em mãos, o denominado "diário de campo", detivemonos a observar suas maneiras, comportamentos, falas, brincadeiras, gestos, no sentido de acompanhar as formas e as redes de relações que as crianças estabeleciam entre si e com os adultos. Esse período de observação foi central para que pudéssemos definir quais intervenções/técnicas iríamos utilizar junto às crianças.

Sendo assim, elaboramos seis tipos de intervenções, que foram desenvolvidas ao longo de cinco meses. Quanto ao conceito de intervenção, Silva e Oliveira (2000) as definem, como "ações deliberadas no sentido de criar novas, ou conformar, ou acomodar relações entre grupos sociais, culturais, entre pessoas e o ambiente em que vivem" (SILVA e OLIVEIRA, 2000, p. 3).

Diante do limite desse texto, apresentaremos três das intervenções realizadas, conforme caracterização abaixo:

a) Intervenção "O espelho e eu" 
O objetivo dessa primeira intervenção foi o diagnóstico inicial da autoclassificação de cada criança. Procedimento da internação: Foi levado um espelho para a sala de aula e cada criança foi sendo convidada para ver sua própria imagem refletida no espelho. No momento da realização, pedimos que cada criança olhasse com atenção os detalhes do seu corpo. Em seguida foram feitas algumas perguntas: Como é o seu cabelo? Você gosta dele? Você é alto ou baixo? Qual a cor de sua pele? Mudaria algo em você?

b) Intervenção "Representação sobre o cabelo"

O objetivo desta intervenção foi compreender as representações que as crianças elaboravam em relação ao cabelo. Procedimento da intervenção: No primeiro momento, foram oferecidas revistas e imagens de pessoas com cabelos variados. No segundo momento as crianças montaram um cartaz com os tipos de cabelos que representassem o delas.

c) Intervenção "Como vejo meu colega"

O objetivo desta intervenção foi identificar a percepção que cada criança elaborava em relação a seus colegas. Procedimento da investigação: Foi mostrado a criança fotos de todos os seus coleguinhas de sala. Em seguida, questionamos: Qual o colega mais legal? O mais bonito? O mais feio? O mais chato? O mais inteligente? O que menos sabe? Quem tem o cabelo mais bonito? A cor de pele mais bonita?

\section{APRESENTAÇÃO E ANÁLISE DOS DADOS}

Durante o mês de agosto, construímos um olhar mais atento às questões/situações que viriam a contribuir para o desenvolvimento dessa pesquisa e, para isso, dedicamo-nos a observar as relações que as crianças estabeleciam entre pares, as brincadeiras e jogos que realizavam, os momentos em que se organizavam em grupos, os critérios que utilizavam para esta organização, as atividades realizadas dentro e fora da sala de aula, etc. A partir desse olhar, começamos a perceber atitudes de estranhamento, confronto e de certa evitação por parte de algumas crianças em relação a seus colegas. 
A título de ilustração, apresentamos uma dessas situações: Em uma das aulas, a professora convidou todos os alunos para a "rodinha de histórias"; antes, contudo, a docente solicitou que cada criança fizesse um círculo de mãos dadas. Uma das crianças se negou a dar a mão à colega ao lado, pois alegou não gostar dela. Tal fato provocou certo incômodo, posto que, ao nosso ver, as crianças sempre buscavam estar em harmonia com seus pares. Esta situação, portanto, tinha muito a nos dizer.

Passamos a ficar mais atentos frente às crianças que demonstravam atitudes de rejeição para com os colegas. Em um determinado dia de aula, enquanto as observávamos interagindo no momento do recreio, identificamos uma criança que era sempre isolada das brincadeiras e dos momentos de lazer. Quando ela se aproximou dos coleguinhas, ouvimos: "Você não pode brincar com a gente, vai brincar pra lá". A menina afastouse a procura de um outro grupo que de imediato teve a mesma reação. Fizemos o convite para que brincasse conosco e fomos brindados com um lindo sorriso. Em conversa, perguntamos o porquê dos seus coleguinhas não quererem brincar com ela, no que, de forma segura, respondeu: "Eles não gostam de mim, tio! Dizem que sou "perebenta" e que não tomo banho". No final da brincadeira ela indagou: "Você pode brincar comigo todos os dias"? Afirmamos que que sim, mas que da próxima vez convidaríamos as outras crianças para brincarem conosco. A menina saiu em direção a sala, com um semblante feliz por aquele momento.

Apresentaremos, a partir desse momento, três das intervenções realizadas junto às crianças.

\subsection{Intervenção "O espelho e eu"}

Essa intervenção foi realizada no dia 07 de outubro de 2015. Dia de muita ansiedade e expectativas. Chegamos à sala com um espelho dentro de uma sacola e logo perguntaram: "o que tem na sacola, tio"? Falamos que se tratava de uma surpresa e que logo saberiam o que tinha na sacola.

De início tive uma conversa informal acerca das características fenotípicas das pessoas, utilizando como exemplo as nossas próprias 
características físicas. Ao final da conversa, retiramos o espelho da sacola e todos, de imediato, queriam saber o porquê do espelho em sala de aula.

Posicionamos o espelho perto do quadro negro, sobre uma cadeira e dissemos: "Agora cada um vai se olhar e dizer o que está vendo no espelho". Ressaltamos que cada um iria se descrever, dizer como é o cabelo, a cor da pele, o tamanho e o que mais desejasse. Logo sentimos que alguns não gostaram da ideia, mas com o tempo todos foram realizando a atividade e dizendo o que viam.

Neste momento, começamos a chamar as crianças de maneira aleatória. Convidamos a primeira criança, que se demonstrou tímida por ter sido a primeira escolhida. Ela levantou e se posicionou frente ao espelho, olhou atentamente e ficou em silêncio (vamos chamá-la de Criança H").

Pesquisador: Como você se vê?

_ Não sei.

A pergunta é feita de forma mais objetiva: Como você vê seu cabelo, a cor da sua pele, dos seus olhos e sua altura? Ela, de forma tímida responde:

_ Meu cabelo é mal feito, ele é muito embaraçado.

O que é um cabelo bem feito?

_ Um cabelo bem feito é um cabelo liso.

Após esse diálogo, a "Criança H" retornou para o seu lugar e ficou atenta as falas dos demais colega. Aos poucos fomos chamando um por um. A "Criança G.N." demonstrou-se ansiosa para ir até o espelho. Durante o processo, observamos sua expressão de alegria, parecia estar se divertindo com o momento. Quando chegou sua vez, perguntamos: Como se vê? Como é você?

- Meu cabelo é bonito. Quando eu crescer ele vai ficar grande e pra cima. (referindo-se ao corte de cabelo, que os fios ficam arrepiados).

Quando questionamos sobre a cor da pele, ele parou, ficou sem graça, olhou para seu braço e disse que não sabia. Continuou parado frente ao espelho, analisando suas características e depois de alguns minutos pensando, explicou da seguinte maneira: 
_ Têm dias que sou bem branquinho e tem dias que sou bem pretinho. Como assim, você muda de cor?

_ Sim, Tio! Quando fico no sol, eu fico bem preto e quando eu não fico no sol, eu fico bem branquinho.

Imaginando ter nos dado uma explicação "convincente", voltou para seu lugar e continuou se divertindo com o processo que ainda viria a ser concluído pelos demais coleguinhas.

As demais crianças, apresentaram respostas curtas, pontuais e sem maiores descrições. Dentre elas, as Crianças E, P, C e Y, heteroclassificadas como de pele negra, afirmaram que eram brancos. Já as Crianças G, I, L, Fe $\mathrm{Cr}$, também heteroclassificadas como de pele negra, afirmaram, com muita dificuldade e timidez, que eram negras. As Crianças GS., LU e So, heteroclassificadas como de pele branca, disseram, de maneira rápida e tranquila, que gostavam de seus cabelos e que eram brancas. Somente a Criança $S$, de pele negra, se reconheceu como tal, sem nenhum tipo de timidez ou medo.

Tomamos essa primeira intervenção, e o diagnóstico realizado através dela, como o ponto crucial para a elaboração das demais intervenções; ela acabou por direcionar nosso olhar para o que precisava ser visto e discutido junto às crianças. Essa ação possibilitou-nos uma compreensão, mesmo que de forma inicial, do pensamento de cada criança em relação ao modo como elaboravam seu pertencimento étnico-racial e da percepção em torno de seus corpos.

A partir desta intervenção, nos são apresentadas "as ações/atos de internalização", bem descritas por Corsaro (2002), Fazzi (2006) e Trinidad (2011), resultantes de certas representações que circulam no meio social e que são internalizadas pelas crianças, afetando suas estruturas psíquicas, especialmente as crianças negras. No momento da auto declaração, a criança demonstra em sua ação descritiva uma compreensão do que já foi estabelecido como belo e como positivo pela sociedade e, ao mesmo tempo, certos traços/características de seus corpos que são tidos como negativos e feios, a exemplo da cor preta e do cabelo duro. Tomemos como 
exemplo a fala da "Criança H", quando afirma que seu cabelo é "mal feito". Um cabelo "mal feito" implica na existência de seu oposto, um cabelo "bem feito", que quase sempre é o cabelo liso. Quando ela define seu cabelo crespo como "mal feito" e posteriormente o liso como "bem feito", expõe a construção de estereótipos em torno do corpo negro e do cabelo crespo, associando-os a algo ruim, indesejável. Ocorre, nesses termos, uma "interiorização subjetiva", resultado dos "processos de racialização" (FAUSTINO, 2015, p. 58).

A mídia, por exemplo, contribui para esse aprendizado quando apresenta, na maioria das vezes, apenas crianças e adultos com as seguintes características: cor de pele branca, olhos azuis e cabelos lisos. Por meio da mídia, é possível aprender sobre a definição de seus papeis sociais - já que os negros, na maior parte das vezes, são sempre apresentados como empregados, pobres, sem famílias, despossuídos de bens materiais e sem dignidade (TRINIDAD, 2012, p. 128).

A fala da "Criança G.N." nos apresenta mecanismos de resistência e projeções futuras para com seu fenótipo. Quanto à questão da cor da pele, percebe-se certa indecisão no processo de reconhecimento; contudo, de forma criativa, explica as "fases", o "tornar-se branco e negro" que, segundo ele, decorreria da exposição solar: quanto mais sol, mais escura a pele fica e quanto menos sol, menos escura a pele fica. Esta ação remete a um aspecto apresentado por Bento (2012) pois, segundo ela, as crianças se sentem desconfortáveis na aceitação de sua condição, mas não reagem quanto ao negativismo apresentado aos seus estereótipos ou, quando reagem, é no sentido de desejarem mudança.

A ponderação trazida por Bento (2012) nos auxilia na compressão das falas das demais crianças que responderam, de forma pontual e lacônica, cada questão levantada, muitas vezes buscando desviar-se de algo que as incomodavam como, por exemplo, a cor da pele, revelando com muita precisão o que concebem sobre si, o quanto não aceitam o seu pertencimento étnico-racial e, portanto, projetando saídas no sentido de se 
aproximar da "branquitude", do "privilégio simbólico da brancura" (BENTO, 2009).

\subsection{Intervenção "Representação sobre o cabelo"}

Nesta intervenção, tivemos o cuidado na seleção do material, pois as revistas de moda e beleza determinam padrões a serem seguidos em suas campanhas e edições. Sabendo desta questão, tivemos a atenção de escolher revistas que expusessem uma variedade na estética dos cabelos, levando em consideração a própria diversidade dos tipos de cabelos das crianças.

Ao chegarmos em sala de aula, explicamos que faríamos um cartaz coletivo e que para isso utilizaríamos do mesmo espaço para fazermos um único trabalho. Colamos um papel metro sobre o quadro negro e nele faríamos o cartaz, assim intitulado: "Meu cabelo é assim".

Entregamos uma revista e uma tesoura para cada criança e pedimos que cada uma buscasse o cabelo que parecesse com o seu. As crianças ficaram animadas e começaram a realizar a tarefa solicitada. Depois de alguns minutos, perguntamos se haviam cortado as figuras e se já podíamos começar a montar o cartaz. As quantidades de imagens variaram. Algumas crianças cortaram seis, outras cortaram três e teve aquelas que só cortaram uma. Todas com figuras em mãos, começamos a montagem. Chamamos uma por uma, para melhor diálogo no momento da montagem.

Convidamos a "Criança E" até a frente do cartaz. Veio depressa, com cinco recortes em mãos e a felicidade de ter sido a primeira. Abriu a mão e mostrou as figuras recortadas: Mulheres e meninas brancas de cabelo loiro e liso. Esta criança tem o cabelo crespo, escuro e com penteados sempre amarrados. Perguntamos à criança: Esses cabelos parecem com o seu?

_ Não parece com o meu, mas eu gosto deles.

Por que você gosta dele?

_ Por que é liso, loiro e grande.

A menina colou as figuras no mural e retornou para seu lugar. Convidei mais uma criança para colar as figuras, que denomino de "Criança L". 
Quando chegou a frente, mostrou as figuras a serem coladas: Meninas de cabelo liso e de cores variadas. Esta criança tem o cabelo "cacheado". Perguntamos: Esses cabelos parecem com o seu?

_ Não! O cabelo que cortei é liso e o meu é cacheado.

Então, por que escolheu recortar esses?

_ Porque eles são bonitos e eu quis cortar.

As falas das demais crianças, apresentadas abaixo, reafirmam 0 padrão de beleza construído socialmente, ao mesmo tempo em que atualizam o "paradigma étnico da branquitude" (SODRÉ, 2012).

_ Criança Lu (menino, cabelo liso): "Este cabelo parece com o meu porque é preto e liso".

_ Criança S (menina, cabelo cacheado): "Este cabelo parece com o meu porque é longo e bonito".

_ Criança Y (menina, cabelo liso): "Gosto deste cabelo porque é longo e escuro".

_ Criança F (menino, cabelo crespo): "Gosto deste cabelo porque é bonito e escuro".

- Criança Cr (menina, cabelo cacheado): "Gosto deste cabelo porque é bonito e cacheado".

_ Criança G (menino, cabelo liso): "Este cabelo é liso e preto, parece com o meu".

_ Criança lc (menino, cabelo crespo): "Este cabelo é liso e o meu também".

_Criança So (menina, cabelo liso): "Este cabelo parece com o meu".

_ Criança A (menina, cabelo liso): "Eu tenho um cabelo liso e elas também".

_ Criança C (menino, cabelo crespo): "Parece com o meu cabelo. É escuro igual o meu".

_ Criança As (menino, cabelo crespo): "Parece com o meu porque é preto e eu gostei desse cabelo aí".

_ Criança I (menina, cabelo cacheado): "O cabelo parece com o meu, é cacheado e bonito". 
A dupla cor e cabelo opera enquanto sistema de classificação e organiza a percepção das crianças a partir do nosso modelo de classificação racial. Em nosso país, o cabelo e a cor da pele são as marcas mais significativas, ambos são largamente usados no nosso critério de classificação racial para apontar quem é negro e quem é branco em nossa sociedade (GOMES, 2005). Essa dupla (corpo e cabelo), para além de atuar como elemento de "classificação racial" e, portanto, do que significa "ser negro" ou "ser branco" em nosso país (cabelo preto, ruim, cacheado, crespo, "duro" e curto são características do grupo negro; por outro lado, características como cabelo loiro, liso, bom e longo, remetem ao grupo branco), abarca e atualiza certos valores morais, estéticos, epistemológicos, etc., que se fundem no que Bento (2009) denomina de "privilégio simbólico da brancura". É dessa forma que, segundo Mbembe (2018, p. 88), "o branco é, sob vários aspectos, uma fantasia da imaginação europeia que o ocidente se esforçou para naturalizar e universalizar".

Gomes (2005), ao mesmo tempo em que defende que o corpo e cabelo são símbolos importantes para a construção da identidade negra, destaca que em nossa sociedade esses símbolos têm sido utilizados para negar essa identidade, de modo a dificultar que a criança negra produza sua identidade de forma positiva, trazendo como consequência a interiorização de um sentimento negativo ao seu próprio corpo, a seu self.

A partir das falas das crianças é possível afirmar que nelas predomina $o$ desejo da brancura. Em algumas, ao reafirmarem "a brancura" de/em seus corpos; em outras, as de corpos negros, quando os negam, posto que os veem ou os desejam brancos. Todavia, é preciso atentar para o desejo de mudança que muitas crianças aspiram, pois, segundo Gomes,

O cabelo do negro, visto como "ruim", é expressão do racismo e da desigualdade racial que recai sobre esse sujeito. Ver o cabelo do negro como "ruim" e do branco como "bom" expressa um conflito. Por isso, mudar o cabelo pode significar a tentativa do negro de sair do lugar da inferioridade ou a introjeção deste. Pode ainda representar um sentimento de autonomia, expresso nas formas ousadas e criativas de usar o cabelo (GOMES, 2005, p. 151). 
Esse escape apresentado por Gomes (2005) é reiterado dia após dia em sala de aula, pois no decorrer da minha pesquisa, presenciamos aspectos de mudanças no cabelo de alguma das meninas, principalmente na questão do alisamento. Crianças com cabelos pranchados e escovados, expressando o sentimento demonstrado por Gomes (2005), em que essa mudança as direcionam para um outro lado, que corresponde ao padrão de estética valorizado socialmente. Nesse sentido, segundo Vannuchi (2017, p. 67), "diante do ideal branco, o corpo negro pode ser vivido como uma ferida aberta ou um objeto perseguidor. O crime perfeito se consuma justamente quando o negro busca se branquear, o que, no limite, é a negação de si mesmo".

\subsection{Intervenção "Como vejo meu colega"}

Intervenção realizada no dia 25 de novembro. Selecionamos fotos de todos os alunos da classe e as colocamos no computador. Ao chegarmos à sala de aula, avisamos às crianças que faríamos uma atividade, mas que para sua realização cada criança, individualmente, deveria ir à sala de vídeo conversar conosco. Todos ficaram ansiosos. Muitos até se dispuseram a ir primeiro para saber de imediato o que havia na sala.

Diante dos limites desse texto, vamos apresentar os discursos construídos pelas crianças, em relação a dois colegas, heteroclassificados como negro e branco, respectivamente Criança E e Criança So.

A Criança $E$, menina, negra, de cabelos crespos. Desde o início da pesquisa, esteve envolvida nas situações de rejeição por parte dos demais alunos. Aparentava um problema alérgico na pele, pois havia pequenos sinais espalhados nas suas pernas e braços. Características atribuídas pelas crianças à Criança $E$ :

_ Criança G.N.: Ela é feia, burra, chata. Porque é preta, come coisa do chão e não sabe ler.

_ Criança H: A mais feia, a mais burra porque não fala direito. $O$ cabelo é feio porque passa a mão e bagunça. A cor é feia porque ela é toda cheia de ferida. 
_Criança So: A cor da pele mais feia porque tem manchas.

_Criança L: A mais feia e mais chata porque mexe os olhos. (O termo mexe os olhos se refere ao estrabismo, apresentado pela criança)

_Criança I: Mais burra porque não aprende. Cabelo mais feio porque vem sem pentear.

- Criança G: Cabelo feio porque ela nasceu assim. Feia porque pirraça. Cor feia porque é preta. Burra porque não sabe de nada.

_Criança F: Ela é a mais chata porque é uma chatucha. É a mais burra porque é porca. A cor é feia e não gosto. O cabelo é feio e não gosto.

_Criança As: É a mais feia porque não gosto dela. É chata porque sempre me pede um pedaço de massinha. A cor dela é feia porque não se parece com a minha.

A Criança So, menina, branca, tinha cabelo liso, cor escura. Sempre sociável com as crianças, todos queriam estar perto dela. Características que Ihes foram atribuídas pelas demais crianças:

_ Criança G. N.: A mais bonita e inteligente porque sabe ler. Tem o cabelo mais bonito.

_ Criança H: A mais bonita. O cabelo dela é mais bonito porque é solto. A cor mais bonita porque parece a nossa.

_ Criança A: Cabelo mais bonito, porque é liso. Cor mais bonita. Mais inteligente. Mais legal.

_ Criança E: A mais bonita porque é chique, obediente e vem sempre arrumada para a escola.

_ Criança l: O cabelo mais bonito porque é liso e a cor mais bonita porque é branquinha.

_ Criança G: A mais bonita. O cabelo é liso e bonito. A cor bonita porque é branca. Inteligente porque sabe de tudo.

_Criança Y: O cabelo mais bonito porque é preto. A cor mais bonita porque é branca. A mais inteligente porque sabe de tudo.

- Criança F: A mais bonita porque gosto dela. A mais inteligente porque ela é massa. A cor bonita porque gosto. A mais legal porque é legal. 
_ Criança Sam: É a mais bonita porque gosto dela (sussurrou em meu ouvido). É inteligente igual a mim. A cor é bonita porque gosto dela.

Muitas pesquisas que tratam da questão da estética, em relação ao cabelo, corpo e a cor, têm reafirmado os modos como operam o preconceito e a discriminação racial, sobretudo em relação às crianças negras. Na pesquisa de Matos (2011), por exemplo, ela discute como no processo de classificação dos alunos referente às pessoas negras e não negras, as crianças foram demarcando profissões, elogios, características e questões afetivas que cabiam a cada um. Nesse sentido, a autora fez a seguinte afirmação:

Dessa forma, muitas crianças ao participarem das atividades, quando olhavam para os personagens negros e negras (sejam as bonecas e os bonecos, sejam nas imagens), sempre em sua maioria traziam falas relacionadas as classificações de cunho afetivo ou estético. [...]. Quanto às preferências estéticas ficou evidente que o fenótipo negro era visto como feio: cabelos crespos, cor da pele, formato do nariz e da boca eram para as crianças motivo de brincadeira e chacota (MATOS, 2011 , p. 5).

Assim como foi ressaltado por Matos (2011), as questões estéticas e afetivas também permearam as falas das crianças, como se pode observar, a partir da intervenção realizada. O modo como é visto o coleguinha pela outra criança ultrapassa a questão estética, mesmo que esta seja um valor acionado pelas crianças, mas amplia-se para as questões afetivas e de relação.

Percebemos que neste processo as crianças já haviam construído representações do outro, resultado de suas relações em sala de aula, dos momentos de brincadeiras, das atividades por elas realizadas, etc. Por exemplo, quando uma criança afirma que alguém é "burro ou inteligente", nos dá uma ideia de que no período das atividades desenvolvidas em sala de aula a mesma foi qualificando os níveis de acertos e erros apresentados pelo seu colega. Cavalleiro (2014) e Oliveira (2004) revelaram, a partir de suas pesquisas, que há uma distribuição desigual de afeto, por parte das professoras, em relação às crianças negras. No caso de nossa pesquisa, essa 
distribuição desigual de afeto atravessa as relações entre as próprias crianças, impactando os processos de aprendizagem das crianças negras, posto que muitas delas são relegadas à própria sorte. Não à tão elas são consideradas as menos inteligentes. Por outro lado, conforme Cavalleiro (2014, p. 99), "[...] a criança branca é levada a cristalizar um sentimento de superioridade, visto que, diariamente, recebe provas fartas dessa premissa. A escola, assim, atua na difusão do preconceito e da discriminação".

Olhando por esta perspectiva, é triste imaginarmos o desdobramento deste tipo de relação no desenvolvimento futuro dessas crianças, pois para a Criança So, ser tida como a mais legal, a mais inteligente e mais bonita, a faz se sentir mais confiante e segura; mas a questão não é somente essa: como já nos disse Munanga (2005), processos como esses acabam, muitas vezes, desde muito cedo, a ensinar às crianças brancas que elas são superiores às crianças negras. Dessa forma, segundo Bento (2009, p. 39) "uma boa maneira de se compreender melhor a branquitude e o processo de branqueamento é entender a projeção do branco sobre o negro, nascida do medo, cercada de silêncio, fiel guardião dos privilégios".

\section{CONSIDERAÇÕES FINAIS}

As reflexões trazidas pela sociologia da infância e antropologia da criança têm nos permitido pensar a criança como sujeito e ator social de seu processo de socialização, e também construtora de sua infância, de forma plena, e não apenas como objeto passivo desse processo e/ou de qualquer outro. Como nos diz Cohn (2005), o que as crianças sabem difere qualitativamente em relação aos conhecimentos dos adultos. Nesse sentido, segundo a autora, as crianças não sabem menos, elas sabem outras coisas.

Por saberem outras coisas e por produzirem sentidos acerca das relações raciais que vivenciam, a compreensão de seus pontos de vista é fundamental. No caso dessa pesquisa, é possível afirmar que os processos e práticas racistas, sobretudo os que recaem sobre o corpo negro, continuam atuando de forma perversa, à semelhança do que demonstraram Cavalleiro (1998) e Fazzi (2006) em suas pesquisas. O "privilégio simbólico da brancura" 
(BENTO, 2009) produz em muitas crianças negras o desejo em mudar seus corpos, de forma a adequá-los ao padrão de estética valorizado socialmente. Se, por um lado, tal desejo pode significar um mecanismo de "captura" racista, por outro, pode, ambém, sinalizar para as estratégias que as crianças constroem, no sentido de enfrentarem as violências sofridas na/pela escola.

Quanto às concepções e a atuação das crianças negras e não negras, pontuamos o poder argumentativo e de persuasão que elas elaboram, no tocante ao modo como constroem o seu pertencimento étnico-racial. Nos diversos momentos da pesquisa, as crianças se posicionaram ativamente no processo, explicitando o que procuravam saber e, principalmente, se esquivando de acusações, práticas discriminatórias e preconceituosas que as atingiam.

\section{REFERÊNCIAS}

ABRAMOWICZ, A.; CRUZ, A. J.; RODRIGUES, T. C. A educação infantil e processos de racialização. In: PEREIRA, R. S.; PIRES, E. D. P. B. (Orgs.). Infância, pesquisa e educação: olhares plurais. Curitiba: CRV, 2017.

ABRAMOWICZ, A.; OLIVEIRA, F. de. As relações étnico-raciais e a sociologia da infância no Brasil: alguns aportes. In: BENTO, M. A. S. (Org). Educação infantil: igualdade racial e diversidade. São Paulo: CEERT, 2012.

ABRAMOWICZ, A.; OLIVEIRA, F. de. A sociologia da infância no Brasil: uma área em construção. Educação, v. 35, n. 1, p. 39-52, jan./abr. 2010. Disponível em: https://periodicos.ufsm.br/reveducacao/article/view/1602/897; acesso: julho de 2016.

ABRAMOWICZ, A. A pesquisa com crianças em infâncias e a sociologia da infância. In: FARIA, A. L. G. de; FINCO, D. (Orgs.). Sociologia da infância no Brasil. Campinas, SP: Autores Associados, 2011.

ABRAMOWICZ, A.; OLIVEIRA, F. de; RODRIGUES, T. C. A criança negra, uma criança negra. In: ABRAMOWICZ, A.; GOMES, N. L. (Orgs.). Educação e raça: perspectivas políticas, pedagógicas e estéticas. Belo Horizonte: Autêntica, 2010.

ALGARVE, V. A. "Cultura negra na sala de aula: pode um cantinho de africanidades elevar a auto-estima de crianças negras e melhorar o relacionamento entre crianças negras e brancas?". 271 f. Dissertação 
(mestrado em Educação). Programa de Pós-Graduação em Educação, Universidade Federal de São Carlos, 2004.

AMADO, J.; CRUSOÉ, N.; VAZ-RABELO, P. Quadros analíticos da investigação qualitativa em educação. In: AMADO, J. (Org.). Manual de investigação qualitativa em educação. 3 ed. Coimbra, Portugal: Universidade de Coimbra, 2017.

BENTO, M. A. S. A identidade racial em crianças pequenas. In: BENTO, M. A. S. (Org). Educação infantil: igualdade racial e diversidade. São Paulo: CEERT, 2012.

BENTO, M. A. S. Branqueamento e branquitude no Brasil. In: CARONE, I.; BENTO, M. A. S. (Orgs.). Psicologia social do racismo: estudos sobre branquitude e branqueamento no Brasil. 4 ed. Petrópolis, RJ: Vozes, 2009.

CARVALHO, A. F. de; MÜLLER, F. Ética nas pesquisas com crianças: uma problematização necessária. In: MÜLLER, F. (Org.). Infância em perspectiva: políticas, pesquisas e instituições. São Paulo: Cortez, 2010.

CAVALLEIRO, E. dos S. Do silêncio do lar ao silêncio escolar: racismo, preconceito discriminação na educação infantil. 1998 - 240 f. Dissertação (Mestrado em Educação) - Programa de Pós-Graduação em Educação, Universidade de São Paulo, 1998.

CAVALLEIRO, E. dos S. Do silêncio do lar ao silêncio escolar: racismo, preconceito discriminação na educação infantil. 6 ed. São Paulo: Contexto, 2014.

COHN, C. Antropologia da criança. Rio de Janeiro: Zahar, 2005.

CORSARO, W. A. Sociologia da Infância. São Paulo: Artmed, 2011.

CORSARO, W. A. Entrada no campo, aceitação e natureza da participação nos estudos etnográficos com crianças pequenas. Revista Educação e Sociedade. Campinas, v.26, n.91, p. 443-464, maio/ago, 2005. Disponível em: http://www.scielo.br/scielo.php?script=sci_arttext\&pid=s0101-

73302005000200008\&lng=pt\&nrm=iso\&tlng=pt; acesso: maio de 2016.

CORSARO, W. A. Reprodução interpretativa e cultura de pares. In: MÜLLER, F.; CARVALHO, A. M. A. (Orgs). Teoria e prática na pesquisa com crianças: diálogos com William Corsaro. São Paulo: Cortez, 2009.

CORSARO, W. A. A reprodução interpretativa no brincar ao "faz-de-conta" das crianças. Educação, Sociedade e Cultura, Porto, v. 17, p. 113-134, 2002. Disponível em: https://www.fpce.up.pt/ciie/revistaesc/ESC17/17-5.pdf; acesso; junho de 2016.

DELGADO, A. C. D.; MÜLLER, F. Apresentação: Sociologia da Infância pesquisa com crianças. Educação \& Sociedade. v.26, n. 91, p. 351-360, 2005. 
Disponível: http://www.scielo.br/pdf/es/v26n91/a02v2691.pdf; acesso: maio de 2016.

DELGADO, A. C. D. Estudos socioantropológicos da infância no Brasil: caminhos, problematizações e diálogo. In: FARIA, A. L. G. de; FINCO, D. (Orgs.). Sociologia da infância no Brasil. Campinas, SP: Autores Associados, 2011.

FAUSTINO, D. M. Por que Fanon? Por que agora? Frantz Fanon e os fanonismos no Brasil. 261f. Tese (Doutorado em Sociologia), Programa de PósGraduação em Sociologia, Universidade Federal de São Carlos, 2015.

FAZZI, R. de C. O drama racial de crianças brasileiras: socialização entre pares e preconceitos. Belo Horizonte: Autêntica. 2006.

FERREIRA, M. M. M. "Branco demasiado" ou... Reflexões epistemológicas, metodológicas e éticas acerca da pesquisa com crianças. In: SARMENTO, M.; GOUVEA, M. C. S. de (Orgs.). Estudos da Infância: Educação e práticas sociais. 2 ed. Petrópolis, RJ: Vozes, 2009.

FINCO, D.; OLIVEIRA, F. A sociologia da pequena infância e a diversidade de gênero e de raça nas instituições de educação infantil. In: FARIA, A. L. G. de; FINCO, D. (Orgs.). Sociologia da infância no Brasil. Campinas, SP: Autores Associados, 2011.

GAUDIO, E. S.; ROCHA, E. A. C. Relações Étnico-Raciais num contexto de Educação Infantil. Revista Momento, v. 22, n. 1, p. 35-50, jan./jul. 2013. Disponível: https://www.seer.furg.br/momento/article/view/4222; acesso: junho 2016.

GOMES, A. M. R. Outras crianças, outras infâncias? In: SARMENTO, M.; GOUVEA, M. C. S. de (Orgs.). Estudos da Infância: Educação e práticas sociais. 2 ed. Petrópolis, RJ: Vozes, 2009.

GOMES, N. L. Salões étnicos como espaços estéticos e políticos de identidade negra. In: GROSSI, M. P. [et.al.]. Movimentos sociais, educação e sexualidades. Rio de Janeiro: Garamond, 2005.

LEE, N. Vozes das crianças, tomada de decisão e mudança. In: MÜLLER, F. (Org.). Infância em perspectiva: políticas, pesquisas e instituições. São Paulo: Cortez, 2010.

LÜDKE, M.; ANDRE, M. E. D. A. A Pesquisa em educação: abordagens qualitativas.2 ed. Rio de Janeiro: E.P.U., 2013.

MATOS, T. C. F. Preconceito racial em escolas públicas brasileiras: A questão racial na perspectiva das crianças. João Pessoa, 2011.

MBEMBE, A. Crítica da razão negra. São Paulo: n-1 edições, 2018. 
MINAYO, M.C. de S. O desafio do conhecimento: Pesquisa Qualitativa em Saúde. (12a edição). São Paulo: Hucitec-Abrasco, 2010.

MUNANGA, K. Apresentação. In: MUNANGA, K. (Org.) Superando o Racismo na Escola. 2 ed. revisada. - Brasília: MEC/ SECAD- Secretaria da Educação Continuada, Alfabetização e diversidade, 2005.

NASCIMENTO, M. L. B. P. Reconhecimento da sociologia da infância como área de conhecimento e campo de pesquisa: algumas considerações. In: FARIA, A. L. G. de; FINCO, D. (Orgs.). Sociologia da infância no Brasil. Campinas, SP: Autores Associados, 2011.

NUNES, M. D. F. Mandingas da infância: as culturas das crianças pequenas na escola municipal Malê Debalê, em Salvador (BA). 431f. Tese (Doutorado em Educação) - Programa de Pós-Graduação em Educação, Universidade de São Paulo, 2017.

NUNES, M. D. F. Cadê as crianças negras que estão aquiẹ: o racismo (não) comeu. Latitude, vol. 10, n² 2, p. 383-423, 2016. Disponível em:

http://www.seer.ufal.br/index.php/latitude/article/view/2616; acesso: abril de 2018.

NUNES, M. D. F. Sociologia da infância, raça e etnografia: intersecções possíveis para o estudo das infâncias brasileiras. Revista Eletrônica de Educação, v. 9, n. 2, p. 413-440, 2015. Disponível em:

http://www.reveduc.ufscar.br/index.php/reveduc/article/view/1115; acesso; agosto de 2017.

OLIVEIRA, F. de. Um estudo sobre a creche: o que as práticas educativas produzem e revelam sobre a questão racial? 2004.11 12 f. Dissertação (Mestrado em Educação) - Centro de Educação e Ciências Humanas, Universidade Federal de São Carlos, São Carlos, 2004.

PROUT, A. Participação, políticas e as condições da infância em mudança. In: MÜLLER, F. (Org.). Infância em perspectiva: políticas, pesquisas e instituições. São Paulo: Cortez, 2010.

QUEIROZ, D. T. Observação Participante na Pesquisa Qualitativa: Conceitos e Aplicações na área de saúde. Rio de Janeiro: UERJ, 2007.

ROSEMBERG, F. A criança pequena e o direito à creche no contexto dos debates sobre infância e relações raciais. In: BENTO, M. A. S. (Org). Educação infantil: igualdade racial e diversidade. São Paulo: CEERT, 2012.

SANTIAGO, F. "O meu cabelo é assim...igualzinho o da bruxa, todo armado." Hierarquização e racialização das crianças pequenininhas negras na educação infantil, 147f. Dissertação (Mestrado em Educação) - Programa de Pós-Graduação, Universidade Estadual de Campinas, Campinas, 2014.

SARMENTO, M. J. Gerações e alteridade: interrogações a partir da sociologia da infância. Educação \& Sociedade, Campinas, v. 26, n. 91, p. 361-378, 
maio/ago. 2005. Disponível em:

http://www.scielo.br/scielo.php?script=sci_arttext\&pid=S0101-

$73302005000200003 \&$ Ing=pt\&nrm=iso\&tIng=pt; acesso: maio de 2016.

SARMENTO, M. J. Sociologia da infância: correntes e confluências. In:

SARMENTO, M.; GOUVEA, M. C. S. de (Orgs.). Estudos da Infância: Educação e práticas sociais. 2 ed. Petrópolis, RJ: Vozes, 2009.

SILVA, P. B. G. e; OLIVEIRA, M. W. Iniciação de educadores sociais à pesquisa científica. NEAB - Núcleo de Estudos Afro-Brasileiros, Universidade de São Carlos, 2000.

SILVA, S. M. A criança negra no cotidiano escolar. 165f. Dissertação (Mestrado em Educação). Programa de Pós-Graduação em Educação, Universidade Católica do Rio de Janeiro, Rio de Janeiro, 2009.

SODRÉ, M. Reinventando a educação: diversidade, descolonização e redes. Petrópolis, RJ: Vozes, 2012.

SOUZA, E. Q. de. Crianças negras em escolas de "alma branca": um estudo sobre a diferença étnico-racial na educação infantil. 2016. 254f. Tese (Doutorado em Educação) - Programa de Pós-Graduação em Educação, Universidade Federal de São Carlos, São Carlos, 2016.

TRINIDAD, C. T. Identificação étnico-racial na voz de crianças em espaços de educação infantil. 2011.221 f. Tese (Doutorado em Educação) - Faculdade de Educação, Pontifícia Universidade Católica de São Paulo, São Paulo, 2011.

TRINIDAD, C. T. Diversidade étnico-racial: Por uma prática pedagógica na educação infantil. In: BENTO, M. A. S. (Org.) Educação infantil, igualdade racial e diversidade: aspectos políticos, jurídicos, conceituais. São Paulo: CEERT, 2012.

VANNUCHI, M. B. C. C. A violência nossa de cada dia: o racismo à brasileira. In: KON, N. M.; SILVA, M. L. da; ABUD, C. C. (Orgs.). O racismo e o negro no Brasil: questões para a psicanálise. São Paulo: Perspectiva, 2017.

Recebido em: 22 de junho de 2018 Aprovado em: 11 de outubro de 2018 